\title{
A Note on Wage Inequality, Technology, and Trade
}

\author{
Chu-Ping Lo \\ Department of Agricultural Economics, National Taiwan University, Chinese Taibei \\ E-mail: cplo@ntu.edu.tw \\ Received February 24, 2011; revised April 5, 2011; accepted April 25, 2011
}

\begin{abstract}
Zeira (2007) presents a two-country model of endogenous technology and trade, illustrating that trade liberalization reduces wage inequality in developing countries. The result contrasts the current outsourcing trade literature; the conflict is due to the critical assumption made in his model that "the most rewarding technologies are invested first.” If we relax this assumption, or allow the technology frontier to foster labor gains in all existing industries, then Zeira's model is, in fact, consistent with the current outsourcing trade literature.
\end{abstract}

Keywords: Wage Inequality, International Outsourcing Trade

\section{Introduction}

In a two-country model, Zeira (2007) shows that trade liberalization reduces wage inequality in a developing country bur increases wage inequality in a developed country. The technological progress that occurs in the developed country generates a skill-biased technology change in the developed country, but no impact on the labor market in the developing country. The trade liberalization mentioned in Zeira's model can be referred to as international outsourcing trade, because an increase in trade liberalization leads to greater trade in intermediate goods in his model. However, in the literature on international outsourcing trade ${ }^{1}$, an increase in international outsourcing trade or technology development leads to a widening wage inequality not only in the developed countries but also in the less developed countries.

I argue that this conflict between Zeira's (2007) model and the current outsourcing trade literature in terms of the labor market in the less developed countries, may be derived from the critical assumption in Zeira's (2007) model: "the most rewarding technologies are invested first" and that the technology frontier is irrelevant to the developing country. If we allow "the most rewarding technologies are invested lately" or allow the technology frontier to foster labor gains in all existing industries, then the wage inequality of the less developed country is

\footnotetext{
${ }^{1}$ See Feenstra and Hanson (196), Antràs et al. (2006), and Ethier (2005) for theoretical analysis, and Epifani and Gancia (2008), Attanasio et al. (2004), Beyer et al. (1999), and Feenstra and Hanson (1997) for empirical analysis. All of these studies found that openness exacerbates the wage inequality between skilled and unskilled labor in less developed countries.
}

likely to increase with trade expansion.

The next section provides an introduction to Zeira's (2007) model. However, I redefine the relative labor gain in his model and reach a new equilibrium in Section 3. The final section concludes.

\section{The Zeira Model}

Zeira (2007) assumes that there is one final good produced for consumption that is not tradable. This final good is produced by a continuum of tradable intermediate goods. The tradable intermediate goods are produced using two alternative technologies: either unskilled labor or skilled labor. No intermediate good is produced with a combination of skilled and unskilled labor. The developed and less developed countries trade the intermediate goods with each other based on their comparative advantages.

More specifically, the set of traded intermediate goods is $M_{t}$, which is distributed uniformly over $M_{t}$, measured for trade openness as $m_{t}=\int_{M_{t}} d i$. Technology adoption, human capital acquisition, and trade patterns are determined endogenously. The production of one unit of intermediate good $i$ using skilled technologies requires $s(i) / a$ units of skilled labor in the developed country and $s(i)$ in the less developed country.

Zeira (2007) also specifies a variable $f$ to represent the technology frontier, which measures the level of technological progress available to a range of intermediate goods $[0, f]$. He assumes that the populations of the developed and less developed countries are given exogenously by $L_{A}$ and $L_{B}$, respectively. The developed 
country has a larger share of skilled labor in the population than the less developed country as $h_{A}>h_{B}$. Using primitive technologies, the production of one unit of intermediate good $i$, requires $n(i) / a$ unit of skilled labor in the developed country and $n(i)$ in the less developed country. The relative gain of adopting the skilled technology is given by $g(i)=\frac{n(i)}{s(i)}>1$, but at the cost of paying a skill premium for the skilled labor. A key assumption in Zeira's model is that the most rewarding technologies are invented first. Here, the technologies with higher relative gains are researched and invented first, such that $g^{\prime}(i)<0$. This critical assumption implies that the frontier technology has the smallest relative labor gain in replacing unskilled with skilled labor, namely, $g(f)<g(i)$ for all $0<i<f$.

In equilibrium with full specialization, there is a trade threshold $v$. We always have $z_{B}<v<f<1$ to indicate that the less developed country cannot access the frontier technology. The developed country is exporting the set of intermediate goods $M \cap[0, f] \cap[0, v]$, all of which are produced by the skilled labor. The less developed country is exporting intermediate goods $M \cap[v, 1]$, which are produced by unskilled labor as shown in Figure 1, which illustrates the equilibrium conditions for labor markets while $w_{S, A}<a w_{S, B}$. Note that the less developed country produces a set of nontradable intermediate goods $M^{C} \cap\left[0, z_{B}\right]$ by applying skilled labor for domestic use.

\section{Equilibrium}

Zeira (2007) assumes that the developed country is sufficiently more skill abundant and has a lower wage inequality than the less developed country. As illustrated in

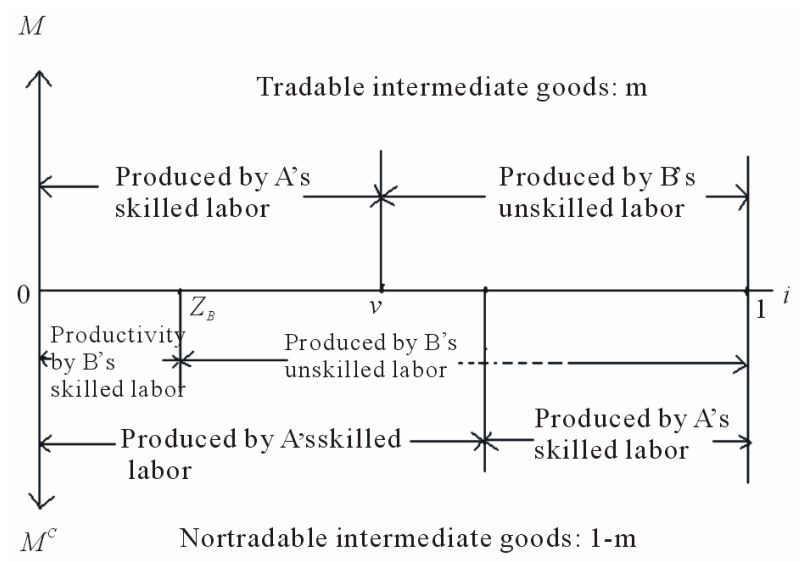

Figure 1. Equilibrium with Full Specialization. Note: A denotes the developed country and $B$ denotes the less developed country.
Figure 1, the equilibrium conditions for skilled and unskilled labor in country A (i.e., the developed country) is given by

$$
\begin{aligned}
L_{A} h_{A} & =\int_{[0, v] \cap M} a^{-1} s(i)\left[X_{A}(i)+X_{B}(i)\right] \mathrm{d} i \\
& +\int_{[0, f] \cap M^{C}} a^{-1} s(i) X_{A}(i) \mathrm{d} i
\end{aligned}
$$

and

$$
L_{A}\left(1-h_{A}\right)=\int_{[f, 1] \cap M^{C}} a^{-1} n(i) X_{A}(i) \mathrm{d} i,
$$

respectively. Similarly, the equilibrium in the market for skilled and unskilled labor in country $B$ (i.e., developing country) are given by

$$
L_{B} h_{B}=\int_{\left[0, z_{B}\right] \cap M^{C}} s(i) X_{B}(i) \mathrm{d} i
$$

and

$$
\begin{aligned}
L_{B}\left(1-h_{B}\right)= & \int_{[v, 1] \cap M} n(i)\left[X_{B}(i)+X_{A}(i)\right] \mathrm{d} i \\
& +\int_{\left[z_{B}, 1\right] \cap M^{C}} n(i) X_{B}(i) \mathrm{d} i
\end{aligned},
$$

respectively. From the equilibrium conditions of these labor markets, we can derive the wage inequality in the two countries ${ }^{2}$. Therefore, in the benchmark case of full specialization in Zeira's model, the wage inequality in the developed country is

$$
W_{A}=\frac{1-h_{A}}{h_{A}} \frac{1-(1-m)(1-f)}{(1-m)(1-f)},
$$

which increases with an increase in trade liberalization $m$. The wage inequality in the less developed country is then determined by

$$
W_{B}=g\left(z_{B}\right)=\frac{1-h_{B}}{h_{B}} \frac{z_{B}(1-m)}{1-z_{B}(1-m)} .
$$

It is the developed country that determines the technology frontier, and the creation of new technology is without cost.

The key assumption in reducing relative labor gains (i.e. $g^{\prime}(i)<0$ ) in Zeira's (2007) model is represented by the downward sloping curve $G$ in Figure 2, while $W_{A}$ and $W_{B}$ are upward sloping. As in (1) and (2), an increase in $m$ shifts $W_{A}$ curve upward and $W_{B}$ curve downward, leading to a higher wage inequality in country $A$ but a lower wage inequality in country $B$. Specifically, $W_{B}$ must reduce with $m$ while $g^{\prime}(i)<0$. It also shows that the development of the frontier technology increases the wage inequality in the developed country, but has no impact on the wage inequality in the developing country.

However, if we relax this critical assumption of "the

\footnotetext{
${ }^{2}$ See Appendix 1 in Zeira (2007) for more details.
} 


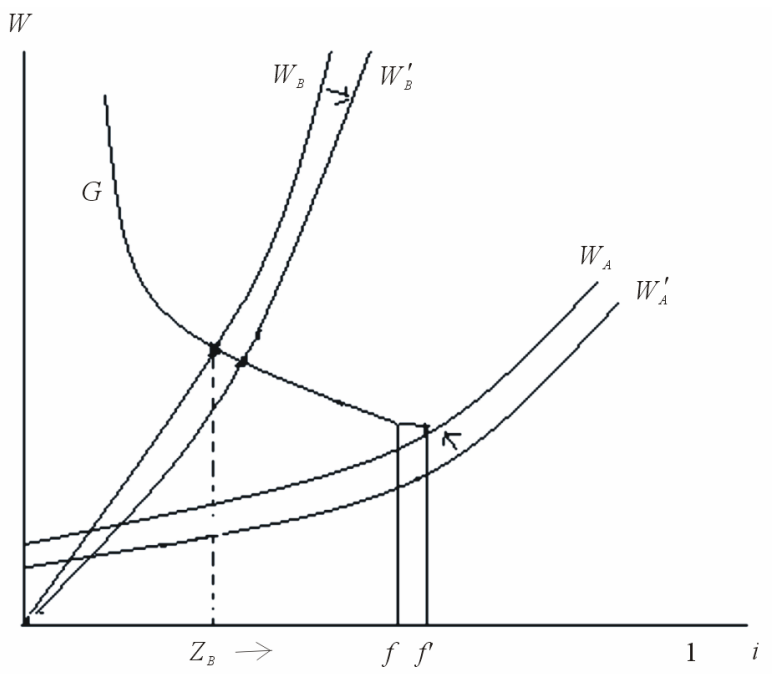

Figure 2. Equilibrium in Zeira's (2007) model.

most rewarding technologies are invested first” and allow the technology with higher relative gains to be invested into later, then the $G$ curve becomes an upward sloping curve while $g^{\prime}(i)<0$ for $0<i<f$. This alternative assumption allows Zeira's (2007) model to correspond with the current literature on outsourcing trade; specifically, that the wage inequality in both the developed and developing country increases with trade liberalization as shown in Figure 3. Nevertheless, technology development is irrelevant to the labor market in the developing country.

Even if it stands to reason that "the most rewarding technologies are invested first,” I argue that Zeira’s (2007) model may still lead to an increase in wage inequality in the less developed country if the trade expansion is due to technology development. Throughout human history, the development of frontier technology usually leads to

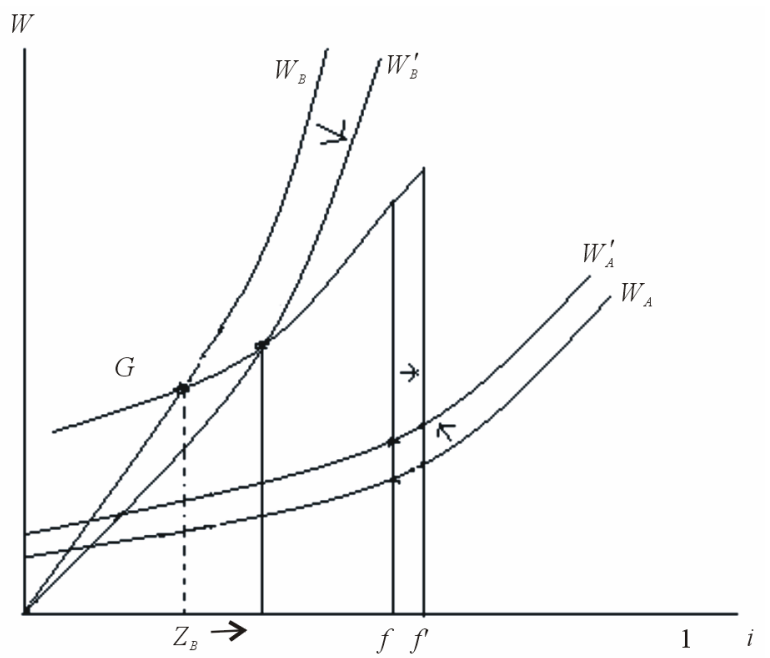

Figure 3 Equilibrium when $g^{\prime}(i)>0$. skill-biased technology changes and improves productivity in all other industries. Evidence for this exists in the following historic events: the Industrial Revolution that occurred during the late 18th and early 19th centuries and the evolution of the Internet and personal computers that took place during the late 20th century.

The Industrial Revolution in Great Britain began with the mechanization of the textile industry through the utilization of steam power, which transferred the primarily manual labor and draft animal-based economy towards machine-based manufacturing. This resulted in a dramatic increase in productivity capacity and spurred the manufacture of increasingly productive machinery for use in other industries (Meier and Rauch, 2000).

Furthermore, the revolutionary development of the Internet and personal computers pushed machine-based manufacturing towards computation-based manufacturing, thus generating more skill-biased technology changes and stimulating productivity improvements in all other industries. While the relative labor gains in the existing industries should increase with the development of the technology frontier, I redefine Zeira's (2007) relative labor gain as $g(i, f)$, where $g_{i}(i, f)<0$ but $g_{f}(i, f)>0$. In this way, the wage inequality in the less developed country is then determined by

$$
W_{B}=g\left(z_{B}, f\right)=\frac{1-h_{B}}{h_{B}} \frac{z_{B}(1-m)}{1-z_{B}(1-m)},
$$

where $g_{z_{B}}\left(z_{B}, f\right)<0$ but $g_{f}\left(z_{B}, f\right)>0$.

Let's assume that the trade barriers are reduced by either the removal of political barriers or the improvement of technologies. Using the Industrial Revolution as an example again, the introduction of steam power, fuelled primarily by coal, expanded world trade enormously by providing a quick and easy way to transport goods, as well as an easy way to transport mail and information through the wide utilization of steam-powered trains and ships (Meier and Rauch, 2000). The innovation prompted by the personal computer and the Internet are fostering more efficient ways of trade and communication as well. Thus, the development of the technology frontier expands trade.

If trade expansion is improved by the reduction of political barriers, as in Zeira's (2007) model, the wage inequality in the developing country decreases with trade as represented by the equilibrium $b$ in Figure 4. However, in contrast to Zeira's model, if trade expansion is induced by the development of technology frontier, I argue that wage inequality in the developing country may increase with trade if the skill-biased technology change is sufficiently large. As shown in Figure 4, an increase in $f$, which shifts the $G$ curve upward, also induces trade expansion, thus shifting the $W_{B}$ curve downward. The 


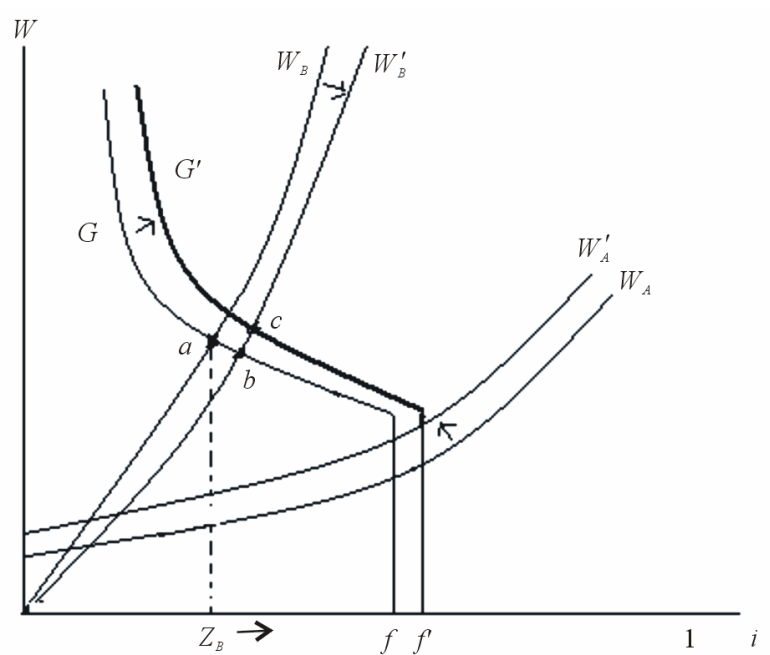

Figure 4. New Equilibrium.

net effect may lead to a new equilibrium $c$, which indicates a higher wage inequality for the developing country than in the initial equilibrium $a$.

\section{Conclusions}

In this paper, I argue that Zeira's (2007) model corresponds with the current literature of outsourcing trade (e.g., Feenstra and Hanson, 1996) if we allow the technology with higher relative gains is to be invested into later. This paper also shows that development in the technology frontier in the developed country induces skill-biased technology change in the labor markets in the developing country through trade.

\section{Reference}

[1] P. Antràs, L. Garicano and E. Rossi-Hansberg, "Offshoring in a Knowledge Economy," Quarterly Journal of Economics, Vol. 121, No. 1, 2006, pp. 31-77.

[2] O. Attanasio, P. K. Goldberg and N. Pavcnik, "Trade Reforms and Wage Inequality in Colombia,” Journal of Development Economics, Vol. 74, No. 2, 2004, pp. 331366. doi:10.1016/j.jdeveco.2003.07.001

[3] H. Beyer, P. Rojas and R. Vergara, "Trade Liberalization and Wage Inequality,” Journal of Development Economics, Vol. 59, No. 1, 1999, pp. 103-123. doi:10.1016/S0304-3878(99)00007-3

[4] P. Epifani and G. Gino, "The Skill Bias of World Trade," Economic Journal, Vol. 118, No. 530, 2008, pp. 927-960. doi:10.1111/j.1468-0297.2008.02156.x

[5] W. J. Ethier, "Globalisation: Trade, Technology, and Wages," International Review of Economics and Finance, Vol. 14, No. 3, 2005, pp. 237-258. doi:10.1016/j.iref.2004.12.001

[6] R. C. Feenstra and G. H. Hanson, "Foreign Investment, Outsourcing and Relative Wages," The Political Economics of Trade Policy: Papers in Honor of Jagdish Bhagwati, MIT Press, Cambridge, 1996, pp. 89-127.

[7] R. C. Feenstra and G. H. Hanson, "Foreign Direct Investment and Relative Wages: Evidence from Mexico’s Maquiladoras," Journal of International Economics, Vol. 42, No. 3-4, 1997, pp. 371-393.

[8] G. M. Meier and J. E. Rauch, "Leading Issues in Economic Development," Oxford University Press, New York and Oxford, 2000.

[9] J. Zeira, "Wage Inequality, Technology, and Trade," Journal of Economic Theory, Vol. 137, No. 1, 2007, pp. 79-103. doi:10.1016/j.jet.2006.03.011 